Article

\title{
Nurses' team communication in hospitals: A quasi-experimental study using a modified TeamSTEPPS
}

\author{
Ahsan Ahsan, Lucky Setiowati, Linda Wieke Noviyanti, Ike Nesdia Rahmawati, \\ Evi Harwiati Ningrum, Kuswantoro Rusca Putra \\ School of Nursing, Faculty of Medicine, Universitas Brawijaya, Malang, Indonesia
}

\begin{abstract}
Background: Communication is a bridge of transaction between the health team, patients, and families that applies in the service units of hospitals, which are closely related to the patient safety culture. TeamSTEPPS is a team strategies and tools to enhance performance and patient safety. Therefore, this study aims to analyze the effect of modified TeamSTEPPS training on the team communication of nurses in hospitals.

Design and Methods: This study used a quasi-experimental pre-post-test control group design and a purposive sampling technique.

Results: About 28 nurses participated and were distributed into control and intervention groups. The results of the Wilcoxon test on communication perception obtained a $\mathrm{p}$-value greater than $\alpha(0.980>0.050)$, while on communication attitudes the $p$-value was greater than $\alpha(0.517>0.050)$. Furthermore, the spearman rho test showed that there was no difference between the team perception $(\mathrm{p}=0.624 ; \alpha=0.050)$ and communication attitudes $(\mathrm{p}=0.320$; $\alpha=0.050$ ). This means that the implementation of this training towards nurses' Team communication in the hospital did not have a significant effect.

Conclusions: Hospitals need to carry out the implementation of TeamSTEPPS in a sustainable manner and develop good teamwork and effective team communication.
\end{abstract}

\section{Introduction}

Patient safety is a major global issue because its incidence is still high. In the United Kingdom, the number of reported incidents increased from 135,356 in October-December 2005 to 508,409 within the same period in $2017 .{ }^{1}$ Research showed that the death rate due to adverse events throughout the United States was around 33.6 million cases, were in the Utah and Colorado regions, the rate of adverse event reached $2.9 \%$ with a death rate of $6.6 \%$, and in New York, it reached $3.7 \%$ with a mortality rate of $13.6 \% .^{2}$

In Indonesia, data on patient safety incidents is still fluctuat- ing. The Hospital Patient Safety Committee (KKP-RS) in Indonesia explained that there were 145 incidents in 2007, 61 in 2008, 114 in 2009, 103 in 2010, and 34 in 2011. Moreover, the provinces that had the highest incident were Jakarta which reached $37.9 \%$, and East Java, which reached $11.7 \%{ }^{3}$ The high incidence of patient safety has a very broad impact. In hospitals, it causes various detrimental impacts, such as disability, injury, and even death, on staffs, and especially the patients that are the recipients of health services. ${ }^{4}$ However, the impacts of the incidents can be prevented by promoting good communication between health workers. ${ }^{5}$ Communication of all information related to patients' condition and development is an important and fundamental component of patient safety because communication is a transaction bridge between the health team, patients, and families. ${ }^{6}$

Many teamwork and communication failures are the main causes of medical errors, including those that occur in operating rooms and lead to sentinel events. ${ }^{5}$ Furthermore, the occurrence of medical accidents is due to poor communication, which is not only caused by the ineffective exchange of information, however, it is also due to differences in hierarchy, superior influence, and interpersonal power. ${ }^{7}$ Ineffective communication can lead to delays in care, and medication and surgical errors. ${ }^{8}$ Therefore, improving communication using the Situation, Background, Assessment, Recommendation (SBAR) method can improve the quality of patient safety. ${ }^{9}$

Barriers that lead to ineffectiveness in communication include low competence among health workers, minimal skills and training on patient safety, and lack of coordination and team performance. ${ }^{10}$ Therefore, nurses' awareness about the importance of improving the quality of their service is needed to reduce patient safety incidents. Besides, one way they can improve this quality is by participating in patient safety training. One of the training interventions proven to be effective for building and improving the communication skills of health workers is Team Strategies and Tools to Enhance Performance and Patient Safety (TeamSTEPPS). ${ }^{11}$

TeamSTEPPS is a systematic approach used to improve quality, safety, and efficiency in health care, and reduce errors. This system focuses on specific skills that are useful to support team

Significance for public health

Team communication is a critical component in the healthcare delivery process, especially among nurses that provide the most care to patients. Many studies have shown that failure in team communication would cause numerous hazardous impacts on patients. These include medical errors, and adverse and sentinel events. The implementation of modified TeamSTEPPS is highly expected to promote better communication and interprofessional collaboration, thus, prevent the incidence of medical errors and patient safety. This study analyzes the effect of the implementation of a modified TeamSTEEPS on Nurses' team communication. The results would provide potential strategies to improve safety in hospitals and other healthcare institutions. 
performance principles, such as specific training, behavioral methods, human factors, and cultural change designed to improve patient safety. ${ }^{12}$ Team STEPPS consists of four components of important skills that need to be learned, including leadership, mutual support, situation direction, and effective communication between team members. ${ }^{13}$

According to various research, TeamSTEPSS is an effective approach for improving patient safety. Furthermore, a study showed that there was an increase of $85 \%$ in teamwork ability and $67 \%$ in communication after health workers received this approach of training. ${ }^{14}$ Also, the implementation of this training is very effective in improving patient safety culture as indicated by the increase in communication, handoffs, transition, and the decrease in the frequency of reports on adverse events. ${ }^{15,16}$ Consequently, the objective of this study was to analyze the effect of applying a modified TeamSTEPPS training on the team communication of nurses in a hospital.

\section{Design and Methods}

This was a quasi-experimental study with a pre-post-test control group design, and it was conducted at two general hospital in East Java, Indonesia: the University of Muhammadiyah Malang Hospital (control group) and Universitas Brawijaya Hospital (intervention group) from November 2019 to February 2020. Samples were obtained using a purposive sampling technique that was based on inclusion and exclusion criteria. The inclusion criteria were nurses who were willing to take part in the research, worked in an inpatient unit for at least 2 months, performed nursing care directly to patients, and worked more than 7.5 hours per week. Meanwhile, the exclusion criteria were nurses who were on leave and still in the experimental stage.

The participants were randomly assigned to control and experimental groups. Furthermore, both groups were given a pre-test, then the TeamSTEPPS training was implemented in only the intervention group. Finally, a post-test was carried out in both groups. The training was conducted by providing materials on 5 components namely teamwork, leadership, communication, mutual support, and situation monitoring, followed by a workshop. The results were analyzed using the independent $t$-test to determine the effect of the training on team communication.

The instruments were the TeamSTEPPS Teamwork Perceptions Questionnaire (T-TPQ) and TeamSTEPPS Teamwork
Attitude Questionnaire (T-TAQ), which consisted of 18 question items, and had been translated into Indonesian. The validity and reliability tests were carried out using Pearson correlation, with a significance of $5 \%$ on 43 participants outside the sample, that had the same characteristics as the sample. The items were valid when the value of the $r$ count was greater than that of the $r$ table $(0.301)$. The Validity test showed that T-TPQ was 0.654 to 0.904 , while TTAQ was 0.320 to 0.573 . Therefore, it was concluded that the questionnaire items on T-TPQ and T-TAQ were valid.

\section{Results and Discussions}

The total sample used in this study was 56 nurses, and they were equally (28 each) assigned to the control and intervention groups. However, based on gender there were more women than men, as 16 respondents in the control group and 23 in the intervention group were females (Table 1). The majority of respondents both in the control group and intervention group were between 20 to 30 years old. Furthermore, the most recent education of respondents in the control group was majorly diploma in nursing, worked in inpatient units, and had a length of service in the unit between 1 to 5 years.

Based on the Wilcoxon test results, this study showed that there was no difference before and after the TeamSTEPPS training in both communication perceptions $(\mathrm{p}=0.332, \alpha=0.050)$ and attitudes $(p=0.626, \alpha=0.050)$ (Table 2). Furthermore, the spearman rho test results showed that there was no difference between the team perception $(\mathrm{p}=0.624, \alpha=0.050)$ and communication attitudes $(p=0.320, \alpha=0.050)$ of the intervention group where the TeamSTEPPS training was implemented and the control group (Table 3). Therefore, it means that the implementation of TeamSTEPPS training on nurses' team communication in the hospital did not have a significant effect.

The nurses' team communication in the control group showed no significant differences between pretest and posttest in both perception and attitude. This was in line with Shaw's research which stated that there was no significant difference between the pre-test and post-test scores of nurses' communication perceptions and attitudes in the control group. Besides, this was because the control group did not receive any training, which means there was no stimulus in the group. ${ }^{17}$ This was in accordance with the Law of Response by Analogy proposed by Thorndike, which explained that individuals tend to react and respond to the events they face.

Table 1. Characteristics of respondents.

\begin{tabular}{|c|c|c|c|c|}
\hline \multirow{2}{*}{ Characteristics } & \multicolumn{2}{|c|}{ Control group ( $\mathrm{n}=28)$} & \multicolumn{2}{|c|}{ Intervention group $(\mathrm{n}=28)$} \\
\hline & $\mathrm{F}$ & $\%$ & $\mathrm{~F}$ & $\%$ \\
\hline \multicolumn{5}{|l|}{ Gender } \\
\hline Male & 12 & $42.9 \%$ & 5 & $17.9 \%$ \\
\hline Female & 16 & $57.1 \%$ & 23 & $82.1 \%$ \\
\hline \multicolumn{5}{|l|}{ Age } \\
\hline 20-30 years & 23 & $82.1 \%$ & 20 & $71.4 \%$ \\
\hline $31-40$ years & 5 & $17.9 \%$ & 8 & $28.6 \%$ \\
\hline \multicolumn{5}{|l|}{ Education } \\
\hline Bachelor & 13 & $46.4 \%$ & 16 & $57.1 \%$ \\
\hline Diploma & 15 & $53.6 \%$ & 11 & $39.3 \%$ \\
\hline Others & 0 & $0.0 \%$ & 1 & $3.6 \%$ \\
\hline \multicolumn{5}{|l|}{ Length of Wwork } \\
\hline$<1$ year & 0 & $0.0 \%$ & 10 & $35.7 \%$ \\
\hline 1-5 years & 22 & $78.6 \%$ & 18 & $64.3 \%$ \\
\hline $6-10$ years & 6 & $21.4 \%$ & 0 & $0.0 \%$ \\
\hline
\end{tabular}


Table 2. Results of the pre-test and post-test of nurses' team communication.

\begin{tabular}{|c|c|c|c|c|}
\hline Group & Variable & Mean & $\mathbf{N}$ & Standard Deviation \\
\hline Control & $\begin{array}{l}\text { Pre-test } \\
\text { Perception } \\
\text { Attitude } \\
\text { Post-test } \\
\text { Perception } \\
\text { Attitude }\end{array}$ & $\begin{array}{l}28.89 \\
23.85 \\
\\
\\
29.17 \\
23.53\end{array}$ & $\begin{array}{l}28 \\
28 \\
\\
28 \\
28\end{array}$ & $\begin{array}{l}3.624 \\
3.014 \\
\\
5.070 \\
2.588\end{array}$ \\
\hline Intervention & $\begin{array}{l}\text { Pre-test } \\
\text { Perception } \\
\text { Attitude } \\
\text { Post-test } \\
\text { Perception } \\
\text { Attitude }\end{array}$ & $\begin{array}{l}29.32 \\
24.07 \\
\\
28.35 \\
24.50\end{array}$ & $\begin{array}{l}28 \\
28 \\
\\
28 \\
28\end{array}$ & $\begin{array}{l}3.356 \\
2.493 \\
\\
\\
3.033 \\
2.962 \\
\end{array}$ \\
\hline
\end{tabular}

Table 3. Results of the difference of nurses' team communication between intervention group and control group.

\begin{tabular}{llllll} 
Variables & Groups & Nean & Z & P \\
Perception & Control & 29.52 & 28 & -0.491 & 0.624 \\
& Intervention & 27.48 & 28 & -0.994 & 0.320 \\
Attitude & Control & 26.38 & 28 & 28 & \\
& Intervention & 30.63 & & \\
\hline
\end{tabular}

Thus, without any stimulus in the form of training to improve nurse communication in the control group, a person would only display existing cognitive skills. ${ }^{18}$

In this study, there were differences in the pre-test and post-test values on communication perceptions and attitudes in the intervention group. However, the difference was not significant and may be due to a lack of training time. This was in line with Shaw's research which stated that there was no significant difference between pre- and post-survey, especially in communication perception variables, due to limited training time. ${ }^{17}$ The duration of the workshop was less than the AHRQ standard, as this study only ran for 2 hours. Meanwhile, based on AHRQ standards, the TeamSTEPPS workshop can be held for 4-6 hours on the second day, after giving the material on the first day. Also, the absence of observation and follow-up action after the training was also one of the supporting factors.

As stated by previous studies, ${ }^{12,19}$ this study also found that the attitude of nurses towards team communication in the intervention group showed that the average of the post-test score was higher than the pre-test. In another study, age also affects nurses' performance, which in turn affects their attitudes and perceptions in applying the knowledge and communication skills they have in the patient safety culture. ${ }^{20}$ Most of the respondents in this study were 20 to 30 years old, and according to another study, the young adult age group of 20 to 30 years, is very productive. ${ }^{21}$

In the intervention group, even though there was an increase in communication attitudes, however, there was a decrease in communication perception. Khademian and Cooked also stated that communication attitudes improved after the TeamSTEPPS training, due to the high interest of the participants in the training. ${ }^{19,22}$ Similarly, Curtsinger stated in a research that the value obtained in the post-survey on communication perception decreased by $0.02 \%$, however, it was assumed this decrease occurred due to the lack of discussion activities during the training. ${ }^{23}$ Factors that influenced the insignificance of the results in this study were due to two main factors: the lack of commitment and motivation of nurses. ${ }^{24}$ At the time of training, some participants were less disciplined, such as being late, going in and out of the room while the training was being conducted, and returning home when the training hours were not yet over. When the timing of the training is not accurately determined, it can lead to less effective results. This can be seen in the case of nurses that left the training before it was over due to shift work schedules. This discovery was in line with previous studies which explained that training sessions need to be scheduled at a time that does not interfere with the shift schedule, as this could encourage the success of the TeamSTEPPS training. ${ }^{25,26}$ From the description above and supported by several existing studies, it can be stated that the implementation of TeamSTEPPS has no significant effect on team communication behavior in the hospital.

\section{Conclusions}

The unsuccessful implementation of TeamSTEPPS in this study may be due to the duration of the training, which was less than the AHRQ standard because the training time was adjusted to ensure that it does not conflict with the shift schedule of nurses at the hospital. Furthermore, it may be due to the lack of commitment and motivation of nurses to participate until the end of training time. It is recommended in further study that the training sessions need to be scheduled at a time that does not interfere with the shift schedule, as this would lead to better results and make it possible for other variables such as patient safety culture and the quality of care to be analyzed adequately. 
Correspondence: Ahsan Ahsan, School of Nursing, Faculty of Medicine, Universitas Brawijaya, Jl. Puncak Dieng, Kunci, Kalisongo, Kec. Dau, Malang, East Java 65151 Indonesia. Tel. +62.341569117 - Fax: +62.341564755.

E-mail: ahsanpsik.fk@ub.ac.id

Key words: Communication; TeamSTEPPS; nursing management.

Contributions: AA, LWN, verified the method and design of this study, and supervised the findings; LS, performed the statistical analysis and interpreted the data; INR, drafted, wrote, and revised the manuscript with support from the other authors; EHN, conceived of the presented idea and developed the theory and concept. All the authors carried out the study and agreed to the arrangement of authors in this study, have read and approved the final version of the manuscript and agreed to be accountable for all aspects of the work.

Conflicts of interests: The authors declare that they have no competing interests, and all authors confirm accuracy.

Funding: Funds were provided by the Faculty of Medicine, Universitas Brawijaya through the Professor and Doctor Grant Scheme (Number: 11/UN10.F08/PN/2019).

Acknowledgment: The authors are grateful to all that contributed to this study, especially the respondents, students of the bachelor program in nursing, Faculty of Medicine, Universitas Brawijaya.

Ethical approval: This study was approved by the Health Research Ethics Commission of the Faculty of Medicine, Universitas Brawijaya (Ethical Clearance letter No. 07/EC/KEPK/01/2020).

Conference presentation: Part of this study was presented at the $1^{\text {st }}$ International Nursing and Health Sciences Symposium, November $13^{\text {th }}$ to $15^{\text {th }} 2020$, Brawijaya University, Malang, Indonesia.

Received for publication: 14 January 2021.

Accepted for publication: 15 March 2021.

oCopyright: the Author(s), 2021

Licensee PAGEPress, Italy

Journal of Public Health Research 2021;10:2157

doi:10.4081/jphr.2021.2157

This work is licensed under a Creative Commons Attribution NonCommercial 4.0 License (CC BY-NC 4.0).

\section{References}

1. National Health Service (NHS). NRLS national patient safety incident reports: commentary. London: NHS; 2018.

2. Institute of Medicine (US) Committee on Quality of Health Care in America; Kohn LT, Corrigan JM, Donaldson MS, editors. To Err is Human: Building a Safer Health System. Washington (DC): National Academies Press (US); 2000.

3. Darliana D. [Hubungan Pengetahuan Perawat Dengan Upaya Penerapan Patient Safety Di Ruang Rawat Inap Rumah Sakit Umum Daerah Dr. Zainoel Abidin Banda Aceh].[Article in Indonesian]. Idea Nurs J 2016;7:6169.

4. Cahyono JB, Suhardjo B. Building patient safety culture in medical practice. Yogyakarta: Kanisius; 2012.

5. Dingley C, Daugherty K, Derieg MK, et al. Improving patient safety through provider communication strategy enhancements. In: Henriksen K, Battles JB, Keyes MA, et al., Editors. Advances in patient safety: New directions and alternative approaches. Vol. 3: Performance and Tools. Rockville: Agency for Healthcare Research and Quality; 2008.

6. Hughes RG. Patient safety and quality: An evidence-based handbook for nurses. Rockville: AHRQ Publication; 2008.

7. O'Daniel M, Rosenstein AH. Professional communication and team collaboration. In: Hughes RG, editor. Patient safety and quality: An evidence-based handbook for nurses. Rockville: AHRQ Publication; 2008.

8. Kathleen M, Lewton E, Marilyn R. Communication failures: An Insidious contributor to medical mishaps. Acad Med 2004;79:186-94.

9. Shitu Z, Hassan I, Thwe Aung MM, et al. Avoiding medication errors through effective communication in healthcare environment. Malays J Mov Health Exerc 2018;7:113-126.

10. Sukesih S, Istanti YP. [Peningkatan Patient Safety dengan Komunikasi Sbar].[Article in Indonesian]. J Caring Sci 2015;3:141-7.

11. Nur HA, Santoso A. [Komunikasi Interprofesional Dalam Peningkatan Keselamatan Pasien: Systematic Review].[Article in Indonesian]. Jurnal Kepemimpinan dan Manajemen Keperawatan 2018;1:28.

12. Kim LY. The effects of simulation-based TeamSTEPPS interprofessional communication and teamwork training on patient and provider outcomes. PHD Thesis, University of California; 2014.

13. King HB, Battles J, Baker DP, et al. TeamSTEPPSTM: Team strategies and tools to enhance performance and patient safety. In: Henriksen K, Battles JB, Keyes MA, Grady ML, editors. Advances in patient safety: New directions and alternative approaches. Vol 3: Performance and Tools. Rockville: AHRQ Publication; 2008.

14. Agency for Healthcare Research and Quality (AHRQ). Pocket Guide TeamSTEPPS 2.0: Team Strategies \& Tools to Enhance Performance and Patient Safety. [cited 2020 Nov 7]. Available from: https://www.ahrq.gov/sites/default/files/wysiwyg/professionals/education/curriculum-tools/teamstepps/instructor/ essentials/pocketguide.pd.

15. Gaston T, Short N, Ralyea C, et al. Promoting patient safety: Results of a TeamSTEPPS ${ }^{\circledR}$ initiative. J Nurs Adm 2016;46:201-7.

16. Megahed M, Ahmed I. Impact of TeamSTEPPS in intensive care units (ICU-STEPPS). J Hosp Adm 2018;7:14.

17. Staines A, Lécureux E, Rubin P, et al. Impact of TeamSTEPPS on patient safety culture in a Swiss maternity ward. Int J Qual Health Care 2020;32:618-24.

18. Shaw B. Evaluation of the impact of TeamSTEPPS Training on perceptions of teamwork and resilience in the intensive care and perioperative units in a tertiary care hospital. 2015. Student Publications 682. [cited 2020 Nov 7]. Available from: https://epublications.regis.edu/theses/682.

19. Islam MH. Thorndike theory and its application in learning. At-Ta'lim: Jurnal Pendidikan 2015;1:37-47.

20. Cooke M. TeamSTEPPS for health care risk managers: Improving teamwork and communication. J Health Risk Manag 2016;36:35-45.

21. Kusumawati D, Frandinata D. [Hubungan beban kerja dengan kinerja perawat Di ruang IGD RSUD Blambangan Banyuwangi Tahun 2015].[Article in Indonesian]. Jurnal Ilmiah Kesehatan Rustida 2015;2:176-90.

22. Faridah I, Ispahani R, Badriah EL. [Faktor-Faktor Yang Mempengaruhi Penerapan Budaya Keselamatan Pasien (Patient Safety Culture) Pada Perawat Di Rawat Inap Rsu Kabupaten Tangerang].[Article in Indonesian]. Jurnal 
Kesehatan 2019;8:21-39.

23. Khademian Z, Pishgar Z, Torabizadeh C. Effect of training on the attitude and knowledge of teamwork among anesthesia and operating room nursing students: A quasi-experimental study. Shiraz E-Med J 2018;19:e61079.

24. Curtsinger A. Improving teamwork and communication through the use of TeamSTEPPS. OAlib 2018;5:1-7.
25. Jackson TA, Meyer JP, Wang X-H. Leadership, commitment, and culture: A meta-analysis. J Leadersh Organ Stud 2013;20:84-106.

26. Mayer CM, Cluff L, Lin W-T, et al. Evaluating efforts to optimize TeamSTEPPS implementation in surgical and pediatric intensive care units. Jt Comm J Qual Patient Saf 2011;37:365-74. 